Original Article

\title{
Relationship of the mobility of the sacroiliac joint with foot plant pressure
}

\author{
Rebeka Boaventura Guimarães, PT, MSc ${ }^{1}$, Cesario Rui Callou Filho PT, MsC ${ }^{2}$, \\ Alex Rey Norberto, MsC ${ }^{3)}$, Renata Salatini, PT, $\mathrm{PhD}^{4)^{*}}$, \\ Juliana Zangirolami-Raimundo, $\mathrm{MsC}^{3,4)}$, Rodrigo Daminello Raimundo, PT, $\mathrm{PhD}^{4}$ \\ 1) Centro Universitário Dr. Leão Sampaio UNILEÃO, Brazil \\ 2) Universidade de Fortaleza, Brazil \\ 3) Departamento de Ginecologia, Faculdade de Medicina FMUSP, Universidade de São Paulo, Brazil \\ 4) Laboratório de Delineamento de Estudo e Escrita Científica, Faculdade de Medicina do ABC: \\ Avenida Príncipe de Gales, 667, Príncipe de Gales, Santo André, CEP 09060-590, Brazil
}

\begin{abstract}
Purpose] To evaluate mobility of the sacroiliac joint and plantar pressure changes. [Participants and Methods] This was an analytical study comprised of 300 participants, using a functional kinetic evaluation involving the test of standing flexion (SFT), the test of Downing, the test of Gillet, and the analysis of baropodometry. [Results] There was an association between mobility of the sacroiliac joint and the standing center of gravity. However, the mobility of this joint was not associated with plantar pressure and the plantar contact area. [Conclusion] These data suggest that sacroiliac mobility is linked to the center of gravity. This connection may precede sacroiliac dysfunction and may help to improve the accuracy of the tests.

Key words: Sacroiliac mobility, Sacroiliac joint, Plantar pressure
\end{abstract}

(This article was submitted Aug. 5, 2020, and was accepted Nov. 25, 2020)

\section{INTRODUCTION}

The sacroiliac joint is designed to transfer load through the pelvis. This stability depends on two factors: the form and the force closure. The first results from the bone structure of the sacrum and the articular surface that allows the sacroiliac joint to be resistant to force distribution ${ }^{1,2)}$. The second factor, force closure, refers to the additional compressive force required to maintain pelvic stability ${ }^{3,4)}$.

The dynamic process performed by the muscular system depends on the integrity of the ligaments and fascial structure in the sacroiliac area ${ }^{3,5)}$. Dysfunction in any of these mechanisms can cause postural disorders and pain ${ }^{6}$. In this way, joint health is influenced by biomechanical factors that alter joint structures, alignments, movements and overloads ${ }^{7}$.

In order to analyze the dysfunctions of the sacroiliac joint, clinical tests are performed which analyze the mobility of the sacrum and iliacus and can trigger discomfort or increase preexisting pain at the site. The organism that presents some articular dysfunction, undergoes a postural adaptation. This adjustment affects other articulations of different segments, such as the foot ${ }^{8)}$.

A healthy posture depends on the balance, coordination, and harmony of the joints, bones, neural and muscular systems. A healthy posture also depends on the correct biomechanical execution of the movements. Static and dynamic postural responses are automatic and adjustable through stimuli, movements, injuries and efforts; a result from the interaction between the person and the environment ${ }^{9)}$.

Due to the ergonomics, such as orthostatic posture, sitting, or walking, adopted by humans in their daily lives, they have

*Corresponding author. Renata Salatini (E-mail: r.salatini@fm.usp.br)

(C2021 The Society of Physical Therapy Science. Published by IPEC Inc.

(c) (1) $\odot$ This is an open-access article distributed under the terms of the Creative Commons Attribution Non-Commercial No Derivacc) 
been suffering a disordered overload on the bony, articular, muscular and neural structures. Thus, imbalances caused by external and internal factors lead to several musculoskeletal injuries mainly at the trunk, pelvis and lower limbs ${ }^{10)}$.

In order to maintain balance in a standing position, the hip joint moves as much as the ankle joint ${ }^{11)}$. Therefore, the mobilization of the hip causes immediate changes in the pattern of plantar pressure distribution ${ }^{12)}$.

Disorders in the hip can cause changes in static and dynamic balance as result of the interaction between postural proprioceptive afferent mechanisms, motor control, kinesthetic memory and adequate joint mobility ${ }^{13,14)}$.

Identifying the changes in static and dynamic plantar pressure will aid in an earlier and more precise diagnosis and also a more clear-cut management of hip and ankle dysfunctions. So, the aim of this research was to relate the mobility of the sacroiliac joint and plantar pressure by comparing the clinical tests with baropodometry.

\section{PARTICIPANTS AND METHODS}

This is an analytical study carried out from February to June 2018. For the constitution of the sample, all 790 academics were invited to participate in the study. All who agreed to participate were initially included for analysis of the inclusion and exclusion criteria. We included 300 academics, over the age of 18, who signed the Informed Consent Form (ICF). We excluded pregnant women; those with confirmed diagnosis of bursitis, tendinitis, osteoporosis and osteoarthritis in the period of crisis; as well as those who gave up the evaluation.

Initially, each participant filled out a questionnaire with age, gender, weight, height and sociodemographic data.

Afterwards, individuals performed a functional kinetic evaluation, consisting of three tests: Standing Flexion Test (SFT) ${ }^{15)}$, Downing Test, and Gillet Test (also known as the Stork test). The tests will allow verification of the mobility of anatomical structures of the sacrum and iliac ${ }^{16}$. All tests were performed by a single trained evaluator.

The SFT began with the individual in an upright position and the evaluator monitored the bilateral movement of the postero-superior iliac spine with palpation. The individual was then asked to perform a trunk flexion. The test is considered positive on the side that the posterior superior iliac spine moved first, passing to a superior position in comparison to the contralateral one ${ }^{17)}$.

The Downing test was performed with the individual in the supine position, with the medial malleoli in contact. The medial malleolus of the side tested had its position determined in comparison with the opposite malleolus. For this, the leg was positioned in abduction and in external rotation until its maximum and then placed in the neutral position. As the limb is rotated externally, a stretching of the tested leg was expected, which is explained by the movement of the lower anterior inferior iliac stump. The leg was then placed in adduction and at maximum internal rotation and then placed in the neutral position shortly thereafter. An apparent shortening of the tested limb was expected, which can be explained by moving the anterior superior iliac spine upward as the limb rotates internally. When there is a sacroiliac dysfunction, the joint will present a restriction and prevent the movement of the iliac ${ }^{18)}$

To perform the Gillet test, the individual remained standing with his hands on the wall in front of him with the evaluator positioned behind him. The evaluator placed a thumb on the posterolateral superior iliac spine (on the side being evaluated) and the other supported thumb in the midline of the sacrum, at the level of S2. Initially, a hip and knee flexion, on the side of the palpation of the posterolateral iliac spine, was requested for the patient. It is natural for the thumb in the posterolateral iliac spine to move inferiorly in comparison to the thumb resting on the sacrum; the patient was asked to perform a hip hyperextension and the evaluator's thumb should move superiorly in comparison to the opposite thumb ${ }^{18)}$.

To analyze plantar pressure, baropodometry was performed using the Baropodometro Footwork apparatus, which contains $400 \times 400 \mathrm{~mm}$ of active surface, $575 \times 450 \times 25 \mathrm{~mm}$ dimensions, 2,704 calibrated capacitive capacitors, $150 \mathrm{~Hz}$ frequency, maximum pressure per $100 \mathrm{~N}$ capacitor $/ \mathrm{cm}^{2}, 16$-bit analog converter, $7.62 \times 7.62 \mathrm{~mm}$ capacitor measurement, a $3 \mathrm{~kg}$ weight, and $4 \mathrm{~mm} / 5 \mathrm{~mm}$ thickness with rubber.

The individuals were instructed to stand on the platform, motionless and staring at a fixed point in front of their eyes for fifteen seconds to identify plantar pressure in static position. Then, the individuals were instructed to slowly walk past the platform, placing one foot at a time. Through this analysis, the center of gravity was identified.

This research was submitted and approved by the Research Ethics Committee (opinion: 2.368.131), linked to the Instituto Leão Sampaio de Ensino Universitário Ltda.

The data were organized and tabulated in the Excel 2013 program for elaboration of the database and in the program SPSS (Statistical Package for Social Research) version 22.0 for statistical analysis. The Kolmogorov-Smirnov test was used to verify normality of the data. Because the variables were non-parametric, the statistical test Mann-Whitney was used to compare the Right and Left Foot Flexion Test, Gillet Test, and Downing Test for anteversion and retroversion. Pearson's $\chi^{2}$ test was used for association between nominal variables (static and dynamic center of gravity, plantar point of greatest contact, SFT, Gillet and Dowing). A significance level of 0.05 (5\%) was defined for this study, with 95\% confidence intervals.

\section{RESULTS}

The study involved 300 people with a mean age of $22.1 \pm 3.7$ years, mean weight of $66 \pm 12 \mathrm{~kg}$, and mean height of 1.63 $\pm 0.07 \mathrm{~m}$. Of the 300 participants, 71 percent were female and 29 percent were male. 
Data from clinical and baropodometric tests are presented by means of median and percentage. There was no statistical difference between left and right foot variables (Table 1).

In Table 1, through the analysis of the STF and the baropodometric findings, the data collected presented medians very similar to the mean total pressures of the left and right foot, respectively, without significant statistical difference ( $p>0.05)$ in association with the domains of baropodometry and the SFT. In the Downing and Gillet Tests, the comparison between the positive laterality of the test did not show any difference in baropodometry.

The data indicated in Table 2 show an association between the location of the static center of gravity and the SFT, and the Gillet and Downing Tests. The association presented statistical significance $(\mathrm{p}=0.015)$. In Table 3 , the association between the location of the dynamic center of gravity and the SFT, and Gillet and Downing Tests was addressed. In this case, there was no statistical significance.

Table 4 shows the absence of statistical significance in the relationship between the plantar point of greater dynamic contact of the right and left lower limbs and the Standing Flexion Tests $(p=0.262)$, Gillet $(p=0.370)$, and Downing $(p=0.370)$.

Table 1. Comparison between pressure and baropodometry contact area and clinical tests

\begin{tabular}{|c|c|c|c|c|c|c|c|c|}
\hline & \multicolumn{4}{|c|}{ Standing flexion test } & \multicolumn{4}{|c|}{ Gillet and Dowing tests } \\
\hline & & \multirow{2}{*}{ Median } & \multicolumn{2}{|c|}{ Percentiles } & & \multirow{2}{*}{ Median } & \multicolumn{2}{|c|}{ Percentiles } \\
\hline & & & 25 & 75 & & & 25 & 75 \\
\hline \multirow[t]{2}{*}{ Total mean pressure $\mathrm{D}$ in static (kPA) } & Right & 50 & 45 & 53.5 & Ante & 50 & 46 & 53 \\
\hline & Left & 50 & 44 & 54 & Retro & 50 & 45 & 55 \\
\hline \multirow[t]{2}{*}{ Total mean pressure $\mathrm{E}$ in static $(\mathrm{kPA})$} & Right & 50 & 46.5 & 55 & Ante & 50 & 47 & 54 \\
\hline & Left & 50 & 46 & 56 & Retro & 50 & 45 & 55 \\
\hline \multirow{2}{*}{$\begin{array}{l}\text { Maximum average pressure total D } \\
\text { in dynamic }(\mathrm{kPA})\end{array}$} & Right & 162.74 & 136.01 & 196.115 & Ante & 164.56 & 141.29 & 196.45 \\
\hline & Left & 166.88 & 145.77 & 196.34 & Retro & 167.065 & 138.88 & 196.03 \\
\hline Mean total maximum pressure & Right & 167.05 & 145.93 & 192.33 & Ante & 165.64 & 147.08 & 193.55 \\
\hline E in dynamic $(\mathrm{kPA})$ & Left & 165.79 & 148.44 & 191.61 & Retro & 166.98 & 145.50 & 189.94 \\
\hline \multirow{2}{*}{$\begin{array}{l}\text { Contact surface area D in } \\
\text { dynamics }\left(\mathrm{cm}^{3}\right)\end{array}$} & Right & 89.32 & 76.27 & 106.43 & Ante & 89.03 & 77.28 & 105.99 \\
\hline & Left & 89.9 & 79.46 & 110.2 & Retro & 90.19 & 75.98 & 110.05 \\
\hline \multirow{2}{*}{$\begin{array}{l}\text { Contact surface area and } \\
\text { dynamics }\left(\mathrm{cm}^{3}\right)\end{array}$} & Right & 89.9 & 75.98 & 102.95 & Ante & 89.03 & 76.12 & 102.66 \\
\hline & Left & 90.48 & 78.88 & 108.46 & Retro & 92.8 & 79.31 & 108.46 \\
\hline
\end{tabular}

Mann-Whitney Test; SFT: Standing flexion test; Gillet: Gillet test; Dowing: Dowing test; Ante: Anteversion; Retro: Retroversion; p: p-value.

Table 2. Location of the static center of gravity associated with SFT, Gillet and Dowing

\begin{tabular}{llccccc}
\hline & & Forefoot R & Forefoot L & Forefoot R & Forefoot L \\
$\mathrm{n}(\%)$ & $\mathrm{n}(\%)$ & $\mathrm{n}(\%)$ & $\mathrm{p}$ & \\
\hline \multirow{2}{*}{ SFT } & Right & $17(8.3)$ & $15(7.3)$ & $87(42.4)$ & $86(42)$ & $0.05^{*}$ \\
& Left & $4(4.2)$ & $7(7.4)$ & $46(48.4)$ & $38(40)$ & \\
\multirow{2}{*}{ Gillet } & Anteversion & $15(8.3)$ & $21(7.3)$ & $81(42.4)$ & $79(42)$ & $0.01^{*}$ \\
& Retroversion & $6(4.2)$ & $1(7.4)$ & $52(48.4)$ & $45(40)$ & \\
\multirow{2}{*}{ Dowing } & $15(8.3)$ & $21(7.3)$ & $81(42.4)$ & $79(42)$ & $0.01^{*}$ \\
& Anteversion & $6(4.2)$ & $1(7.4)$ & $52(48.4)$ & $45(40)$ &
\end{tabular}

Pearson $\chi^{2}$, SFT: Standing flexion test; Gillet: Gillet test; Dowing: Dowing test.

Table 3. SFT, Gillet location of the center of gravity in the dynamics associated with e Dowing

\begin{tabular}{llcccl}
\hline \multirow{2}{*}{ SFT } & & $\begin{array}{c}\text { Forefoot R } \\
\mathrm{n}(\%)\end{array}$ & $\begin{array}{c}\text { Forefoot L } \\
\mathrm{n}(\%)\end{array}$ & $\begin{array}{c}\text { Forefoot R } \\
\mathrm{n}(\%)\end{array}$ & $\begin{array}{c}\text { Forefoot L } \\
\mathrm{n}(\%)\end{array}$ \\
\hline \multirow{3}{*}{ Gillet } & Right & $89(43.4)$ & $103(50.2)$ & $8(3.9)$ & $5(2.4)$ \\
& Left & $42(44.2)$ & $42(44.2)$ & $10(10.5)$ & $1(1.1)$ \\
& Anteversion & $84(41)$ & $97(47.3)$ & $11(5.4)$ & $4(2)$ \\
& Retroversion & $47(49.5)$ & $48(50.5)$ & $7(7.4)$ & $2(2.1)$ \\
& Anteversion & $84(41)$ & $97(47.3)$ & $11(5.4)$ & $4(2)$ \\
& Retroversion & $47(49.5)$ & $48(50.5)$ & $7(7.4)$ & $2(2.1)$ \\
\hline
\end{tabular}

Pearson $\chi^{2}$, SFT: Standing flexion test; Gillet: Gillet test; Dowing: Dowing test. 
Table 4. Comparison of the plantar point of greater dynamic contact and the SFT, Gillet and Dowing

\begin{tabular}{|c|c|c|c|c|c|c|c|c|c|c|c|c|c|}
\hline & & $\begin{array}{c}\text { Forefot } \\
\text { R }\end{array}$ & $\begin{array}{c}\text { Forefoot } \\
\text { L }\end{array}$ & $\begin{array}{c}\text { Forefoot } \\
\text { Both }\end{array}$ & $\begin{array}{c}\text { Forefoot } \\
\text { Both } \\
\text { Hind- } \\
\text { foot R }\end{array}$ & $\begin{array}{l}\text { Forefoot } \\
\text { Both } \\
\text { Hind- } \\
\text { foot L }\end{array}$ & $\begin{array}{l}\text { Halux, } \\
\text { Forefoot } \\
\text { Both }\end{array}$ & $\begin{array}{c}\text { Halux, } \\
\text { Lateral } \\
\text { R }\end{array}$ & $\begin{array}{l}\text { Halux, } \\
\text { Lateral } \\
\text { L }\end{array}$ & $\begin{array}{l}\text { Halux, } \\
\text { Forefoot } \\
\text { R }\end{array}$ & $\begin{array}{l}\text { Halux, } \\
\text { Forefoot }\end{array}$ & $\begin{array}{c}\text { Hindfoot } \\
\text { Both }\end{array}$ & $\begin{array}{c}\text { Halux, } \\
\text { Forefoot } \\
\text { Both L } \\
\text { and R }\end{array}$ \\
\hline & & $\mathrm{n}(\%)$ & $\mathrm{n}(\%)$ & $\mathrm{n}(\%)$ & n $(\%)$ & $\mathrm{n}(\%)$ & n $(\%)$ & $\mathrm{n}(\%)$ & n (\%) & $\mathrm{n}(\%)$ & & $\mathrm{n}(\%)$ & n $(\%)$ \\
\hline \multirow[t]{2}{*}{ SFT } & Right & $14(6.0)$ & $2(1)$ & $116(56.6)$ & $5(2.4)$ & $1(0.5)$ & $58(28.3)$ & $0(0)$ & $2(1)$ & $1(0.5)$ & $1(0.5)$ & $4(2)$ & $1(0.5)$ \\
\hline & Left & $1(1.1)$ & $0(0)$ & $59(62.1)$ & $0(0)$ & $0(0)$ & $32(33.7)$ & $1(1.1)$ & $0(0)$ & $0(0)$ & $0(0)$ & $2(2.1)$ & $0(0)$ \\
\hline \multirow[t]{2}{*}{ Gillet } & Right & $11(5.4)$ & $2(1)$ & $119(58)$ & $4(2)$ & $1(0.5)$ & $54(26.3)$ & $1(0.5)$ & & $0(0)$ & $0(0)$ & $2(1)$ & $1(0.5)$ \\
\hline & Left & $4(4.2)$ & $0(0)$ & 56 (58.9) & $1(1.1)$ & $0(0)$ & $36(37.9)$ & $0(0)$ & $1(1.1)$ & $1(1.1)$ & $1(1.1)$ & $4(4.2)$ & $0(0)$ \\
\hline \multirow[t]{2}{*}{ Dowing } & Right & $11(5.4)$ & $2(1)$ & $119(58)$ & $4(2)$ & $1(0.5)$ & $54(26.3)$ & $1(0.5)$ & $1(0.5)$ & $0(0)$ & $0(0)$ & $2(1)$ & $1(0.5)$ \\
\hline & Left & $4(4.2)$ & $0(0)$ & $56(58.9)$ & $1(1.1)$ & $0(0)$ & $36(37.9)$ & $0(0)$ & $1(1.1)$ & $1(1.1)$ & $1(1.1)$ & $4(4.2)$ & $0(0)$ \\
\hline
\end{tabular}

Pearson $\chi^{2}$, SFT: Standing flexion test; Gillet: Gillet test; Dowing: Dowing test; R: right; L: Left.

\section{DISCUSSION}

There are few studies correlating sacroiliac joint mobility with baropodometry variables, making this study an innovative approach in evaluating sacroiliac joint dysfunctions associated with possible early imbalances in posture. Among the main results of this study, we verified the change in the static center of gravity related to sacroiliac mobility in young people in the SFT, Gillet and Downing Tests ( $\mathrm{p}=0.05, \mathrm{p}=0.01, \mathrm{p}=0.01$, respectively). This change in the center of gravity may be an early sign for downward dysfunctions and even changes in plantar pressure.

Baropodometry has been shown to be useful in providing data for postural analyzes ${ }^{19)}$ and may contribute to treatment preciseness and preventive actions. In the literature, there is a knowledge gap in the evaluation of the evolution of hip dysfunctions through plantar pressure.

The sacral iliac joint (SIJ) is an important region in relation to the distribution of forces to the lower extremities. This is because the weight of all the superior structures, such as the axial structure, head, and other upper extremities, is directed towards the pelvis and travels through its neighboring soft tissues to the legs and feet ${ }^{20,21)}$.

This relationship is vulnerable to arthrokinetic constraints caused by this constant interaction of descending and upward forces occurring in this region ${ }^{3}$, which may favor SIJ alteration ${ }^{22,23)}$.

Dysfunctions in the sacroiliac region are more prevalent in women due to musculature, iliac positioning, fertility, and body weight, which are accompanied by pain ${ }^{24)}$. In this study, 71 percent of the population were women with a mean age of $22.1 \pm 3.7$.

The age of the participants involved may explain, at least in parts, why an association of sacroiliac mobility with the center of gravity was identified but not with plantar pressure. The age suggests a possible mechanism of early compensation before biomechanical and overload compensations.

It is believed that late adaptations of muscles such as paraespinal could trigger biomechanical offsets of surrounding tissues and potential overload of other structures ${ }^{25,26}$. Changes in the sacral iliac joint can be observed even in asymptomatic individuals in the early stages ${ }^{27}$.

The association of hip mobility with the center of gravity identified in the three tests may be an early stage of such compensations. There were no symptomatic biomechanical compensations since all the patients evaluated in this study were free of pain.

Although the relation of the center of gravity with the plantar pressure is not frequently studied, it has already confirmed ${ }^{28)}$. In a study by Foti and collaborators, the plantar pressure was analyzed of women in the last trimester of pregnancy. Considering the change in the center of gravity due to the increase in weight in the abdominal region, there was an increase in plantar pressure of the foot compared to women who are overweight, of the same age and $\mathrm{BMI}^{29}$ ).

This difference between the groups is because of the change in the center of gravity due to the difference in weight distribution between pregnant women and women that are not pregnant with the same BMI. In addition, because of rapid weight gain during gestation, there may not be enough time for muscle adaptations and biomechanical compensation, in the plantar pressure of these women.

It should be considered that pregnant women also have functional changes in the hip region ${ }^{29,30)}$, which may be another indicator of the relation of the sacroiliac joint to the center of gravity.

The risk factors for sacroiliac dysfunction are still unknown. But factors that contribute to the reported pain in the region ${ }^{31)}$ are gender, sacral positioning, pelvic anatomy, muscle strength and ligament laxity. In the present study, sacroiliac dysfunction was due to biomechanical disorders, originating and/or causing postural compensations, since the patients did not report pain.

The SIJ is little considered in the clinical evaluation ${ }^{32)}$. To assess this joint clinically, several tests are used. However, 
because they are subjective, at least 3 tests are required to confirm the dysfunction of this joint.

It is imperative to use a validated instrument for postural evaluation in order to verify the existing imbalances and to adapt the best posture for each individual, with the possibility of a restructuring of the muscular chains, both static and dynamic ${ }^{33)}$.

When assessing the sacroiliac joints, the examiner seeks signs of asymmetry and altered range of motion through bone palpation and specific clinical tests ${ }^{34)}$.

In this context, it is acceptable that sacroiliac functionality is fundamental for proper weight distribution, by the Sacro wedge shape that allows the force vectors to be homogeneously directed to the iliac partners through the segmented soft tissues and consequently to the lower extremities ${ }^{35)}$.

Thus, it can be inferred that the sacroiliac asymmetry can interfere with the ability to maintain orthostatism and could lead to a consequent alteration of the distribution of the weight between the feet by a non-harmonic relation between the parts of the body, resulting in greater tension and overload in the base support ${ }^{36)}$.

The results found in the present study corroborate that people with sacroiliac dysfunction present balance deficit and postural control due to muscle control and redistribution of plantar pressure and their influence on gait ${ }^{37)}$.

Our study did not identify an association between the domains of plantar pressure baraopodometry, plantar surface contact area, and location of the dynamic center of gravity with the TFP, Gillet Test, and Downing Test. As a result, this demonstrates the lack of association of sacroiliac mobility and plantar pressure. These results may be due to altered muscle activity or postural changes to maintain balance. Increased muscle activity, changes in muscle and joint positioning, and different stimuli may influence peripheral responses ${ }^{38)}$. In contrast, the study identified that $74 \%$ of the women had concomitant sacroiliac dysfunction and plantar pressure changes ${ }^{39)}$.

Evaluation of the peak plantar pressure and the contact area of 20 asymptomatic individuals consisted of using baropodometry before, shortly after, and seven days after sacroiliac manipulation. The study found a positive influence on the distribution of weight between the feet by the normalization of peak pressure immediately after the manipulation and seven days later.

It is suggested that the alterations may be due to proprioceptive strategies adopted by the body that involve ankle and pelvis joint to coordinate the equilibrium responses. However, the contact area seems to be influenced by postural habits due to the strong correlation between the area and the dominant end ${ }^{14)}$.

The SIJ has an influence on the distribution of loads to the lower limbs and relation to the postural balance due to its association with the location of the static center of gravity and postural reorganization ${ }^{10,40}$. The alteration of this articulation generates changes in the load distribution in the musculoskeletal system, which can lead to postural imbalances and balance deficits $^{40)}$.

The measurement of plantar pressure is still not widely used in clinical practice, especially in association with pelvic and trunk joint dysfunctions ${ }^{41)}$. Taking into account that increased plantar pressure triggers biomechanical changes in the lower limbs, pelvis, and spine, baropodometry can perform pressure analysis in each individual participant of the research, convert the data obtained to numbers, and expose through images of the plantar region, where it is possible to identify areas of higher and lower pressure.

The use of the baropodometer is still very limited because factors, such as sensor technology, software resolution, positioning, and calibration of the platform, can influence the standardization and reliability of the data generated by the device. However, clinical tests can be influenced by the evaluator's experience. Their reliability varying from poor to good ${ }^{42,43)}$. Longitudinal studies with intervention on the sacroiliac joint, repercussion on the change in the center of gravity and plantar pressure, and photographic postural evaluation are necessary to better quantify the results.

There was no association between mean plantar pressure, plantar surface contact area, and the location of the center of gravity with the SFT, Gillet and Downing Tests. However, this study is the first to demonstrate the association of the center of gravity through baropodometry with the mobility tests.

\section{Conflict of interest}

The authors declare that there was no conflict of interest or financial support to be declared.

\section{REFERENCES}

1) Vleeming A, Stoeckart R, Volkers AC, et al.: Relation between form and function in the sacroiliac joint. Part I: Clinical anatomical aspects. Spine, 1990, 15: 130-132. [Medline] [CrossRef]

2) Vleeming A, Volkers AC, Snijders CJ, et al.: Relation between form and function in the sacroiliac joint. Part II: Biomechanical aspects. Spine, 1990, 15: 133-136. [Medline] [CrossRef]

3) Snijders CJ, Vleeming A, Stoeckart R: Transfer of lumbosacral load to iliac bones and legs Part 1: Biomechanics of self-bracing of the sacroiliac joints and its significance for treatment and exercise. Clin Biomech (Bristol, Avon), 1993, 8: 285-294. [Medline] [CrossRef]

4) Snijders CJ, Vleeming A, Stoeckart R: Transfer of lumbosacral load to iliac bones and legs Part 2: Loading of the sacroiliac joints when lifting in a stooped posture. Clin Biomech (Bristol, Avon), 1993, 8: 295-301. [Medline] [CrossRef]

5) Mens JM, Vleeming A, Snijders CJ, et al.: The active straight leg raising test and mobility of the pelvic joints. Eur Spine J, 1999, 8: 468-473. [Medline] [CrossRef]

6) Nejati P, Safarcherati A, Karimi F: Effectiveness of exercise therapy and manipulation on sacroiliac joint dysfunction: a randomized controlled trial. Pain Physician, 2019, 22: 53-61. [Medline] 
7) Wolf JM, Cameron KL, Owens BD: Impact of joint laxity and hypermobility on the musculoskeletal system. J Am Acad Orthop Surg, 2011, 19: 463-471. [Medline] [CrossRef]

8) López JC: Relacion entre osteopatia y podologia. Peu. 2001, 4: 182-184.

9) Bankoff AD, Ciol P, Zamai CA, et al.: Estudo do equilíbrio corporal postural através do sistema de baropodometria eletrônica. Conexões (Campinas), 2007, 2: 87-104.

10) Anker LC, Weerdesteyn V, van Nes IJ, et al.: The relation between postural stability and weight distribution in healthy subjects. Gait Posture, 2008, 27 : 471-477. [Medline] [CrossRef]

11) Suzuki Y, Nomura T, Casadio M, et al.: Intermittent control with ankle, hip, and mixed strategies during quiet standing: a theoretical proposal based on a double inverted pendulum model. J Theor Biol, 2012, 310: 55-79. [Medline] [CrossRef]

12) Ferreira GE, Viero CC, Silveira MN, et al.: Immediate effects of hip mobilization on pain and baropodometric variables-a case report. Man Ther, 2013, 18: 628-631. [Medline] [CrossRef]

13) Winter D: Human balance and posture control during standing and walking. Gait Posture, 1995, 3: 193-214. [CrossRef]

14) Grassi DO, de Souza MZ, Ferrareto SB, et al.: Immediate and lasting improvements in weight distribution seen in baropodometry following a high-velocity, low-amplitude thrust manipulation of the sacroiliac joint. Man Ther, 2011, 16: 495-500. [Medline] [CrossRef]

15) Vincent-Smith B, Gibbons P: Inter-examiner and intra-examiner reliability of the standing flexion test. Man Ther, 1999, 4: 87-93. [Medline] [CrossRef]

16) Peres CP, Risso L, Oliveira LU: Efeitos da manipulação do ilíaco na descarga de peso no retropé em indivíduos com disfunção sacro-ilíaca. Man Ther Posturology Rehabil J. 2011, 9: 150-154.

17) Makofsky HW: Coluna vertebral: terapia manual. Rio de Janeiro: Guanabara Koogan, 2006.

18) Ricard F: Sallé J.: Tratado de Osteopatia. Madrid: Médica Panamericana, 2003.

19) Rosário JL: A review of the utilization of baropodometry in postural assessment. J Bodyw Mov Ther, 2014, 18: 215-219. [Medline] [CrossRef]

20) Nourbakhsh MR, Arabloo AM, Salavati M: The relationship between pelvic cross syndrome and chronic low back pain. J Back Musculoskeletal Rehabil, 2006, 19: 119-128. [CrossRef]

21) Vleeming A, Albert HB, Östgaard HC, et al.: European guidelines for the diagnosis and treatment of pelvic girdle pain. Eur Spine J, 2008, 17: 794-819. [Medline] [CrossRef]

22) Maigne JY, Aivaliklis A, Pfefer F: Results of sacroiliac joint double block and value of sacroiliac pain provocation tests in 54 patients with low back pain Spine, 1996, 21: 1889-1892. [Medline] [CrossRef]

23) Hancock MJ, Maher CG, Latimer J, et al.: Systematic review of tests to identify the disc, SIJ or facet joint as the source of low back pain. Eur Spine J, 2007, 16: 1539-1550. [Medline] [CrossRef]

24) DePalma MJ, Ketchum JM, Saullo TR: Multivariable analyses of the relationships between age, gender, and body mass index and the source of chronic low back pain. Pain Med, 2012, 13: 498-506. [Medline] [CrossRef]

25) Brumagne S, Cordo P, Lysens R, et al.: The role of paraspinal muscle spindles in lumbosacral position sense in individuals with and without low back pain Spine, 2000, 25: 989-994. [Medline] [CrossRef]

26) Hungerford B, Gilleard W, Hodges P: Evidence of altered lumbopelvic muscle recruitment in the presence of sacroiliac joint pain. Spine, 2003, 28: 1593-1600. [Medline] [CrossRef]

27) Dreyfuss P, Dryer S, Griffin J, et al.: Positive sacroiliac screening tests in asymptomatic adults. Spine, 1994, 19: 1138-1143. [Medline] [CrossRef]

28) Karadag-Saygi E, Unlu-Ozkan F, Basgul A: Plantar pressure and foot pain in the last trimester of pregnancy. Foot Ankle Int, 2010, 31: 153-157. [Medline] [CrossRef]

29) Foti T, Davids JR, Bagley A: A biomechanical analysis of gait during pregnancy. J Bone Joint Surg Am, 2000, 82: 625-632. [Medline] [CrossRef]

30) Taves C, Charteris J, Wall J: Kinematics of treadmill walking during pregnancy. Physiother Can, 1982, 32: 321-324.

31) Guo JM, Zhang GQ, Alimujiang: [Effect of BMI and WHR on lumbar lordosis and sacrum slant angle in middle and elderly women]. Zhongguo Gu Shang, 2008, 21: 30-31 (in Chinese). [Medline]

32) Moraes M, Marini L, Laccourt M: Índice de disfunção sacro-ilíaca em mulheres com lombalgia. Rev. Ter Man. Man Ther Posturology Rehabil J. 2004, 2 : $98-103$.

33) Teixeira E, Sauron F, Santos L, et al.: Terapia ocupacional na reabilitação física. São Paulo: Rocca, 2003.

34) Greenman PE: Princípios Da Medicina Manual, 2nd ed. São Paulo: Manole, 2001.

35) Mahato NK: Variable positions of the sacral auricular surface: classification and importance. Neurosurg Focus, 2010, 28: E12. [Medline] [CrossRef]

36) Teodori RM, Guirro EC O, Santos RM: Distribuição da pressão plantar E localização do centro de força após intervenção pelo método de reeducação postural global: um estudo de caso. Fisioter Mov, 2005, 18: 27-35.

37) Baruah S, Eapen C, Kamath KR: An association between postural stability and sacroiliac joint pain — a case control study. J Musculoskelet Res, 2013, 16: 135-137. [CrossRef]

38) VanderHill MS, Wolf EE, Langenderfer JE, et al.: The effect of actual and imaginary handgrip on postural stability during different balance conditions. Gait Posture, 2014, 40: 652-657. [Medline] [CrossRef]

39) Campos WP, Santos LB, Antunes MD, et al.: Análise baropodométrica da pressão plantar em mulheres com disfunção biomecânica da articulação sacro-ilíaca. Braz J Surg Clin Res. 2017, 19: 54-59.

40) Farazdaghi MR, Motealleh A, Abtahi F, et al.: Effect of sacroiliac manipulation on postural sway in quiet standing: a randomized controlled trial. Braz J Phys Ther, 2018, 22: 120-126. [Medline] [CrossRef]

41) Giacomozzi C: Appropriateness of plantar pressure measurement devices: a comparative technical assessment. Gait Posture, 2010, 32: 141-144. [Medline] [CrossRef]

42) Meijne W, van Neerbos K, Aufdemkampe G, et al.: Intraexaminer and interexaminer reliability of the Gillet test. J Manipulative Physiol Ther, 1999, 22: 4-9. [Medline] [CrossRef]

43) Paydar D, Thiel H, Gemmell H: Intra- and interexaminer reliability of certain pelvic palpatory procedures and the sitting flexion test for sacroiliac joint mobility and dysfunction. J Neuromusculoskel Syst, 1994, 2: 65-69. 